\title{
Preparation of Amino-Modified PAN Fibers with Triethylenetetramine as Aminating Reagents and Their Application in $\mathrm{CO}_{2}$ Adsorption
}

\author{
Wenbo Zhao, ${ }^{1}$ Biao Liu, ${ }^{1}$ and Jian Chen ${ }^{2}$ \\ ${ }^{1}$ Faculty of Chemical Engineering, Kunming University of Science and Technology, Kunming 650500, China \\ ${ }^{2}$ State Key Laboratory of Chemical Engineering, Department of Chemical Engineering, Tsinghua University, Beijing 100084, China \\ Correspondence should be addressed to Wenbo Zhao; wenshuixing@126.com and Jian Chen; cj-dce@mail.tsinghua.edu.cn
}

Received 26 December 2013; Revised 1 March 2014; Accepted 3 March 2014; Published 1 April 2014

Academic Editor: Yongping Hou

Copyright @ 2014 Wenbo Zhao et al. This is an open access article distributed under the Creative Commons Attribution License, which permits unrestricted use, distribution, and reproduction in any medium, provided the original work is properly cited.

\begin{abstract}
Amino-modified polyacrylonitrile (AMPAN) fiber was synthesized by the reaction of polyacrylonitrile (PAN) fiber and triethylenetetramine (TETA) in the presence of water. The effect of water amount, reaction temperature, and time on the weight increase degree and alkali content of the AMPAN fiber was investigated in detail. The characterization results indicated that TETA could be grafted onto the surface of PAN fiber by this method. However, the highest adsorption capacity of the AMPAN fibers was only $0.09 \mathrm{~g} / \mathrm{g}$ even at 15 bar and $50^{\circ} \mathrm{C}$, which was much lower than the porous materials. The reason for this result may be related to its low surface area.
\end{abstract}

\section{Introduction}

With the development of society and increase of live level, which mainly come from the combustion of fossil fuel and human activities, the excess emission of $\mathrm{CO}_{2}$ has become a worldwide problem. The research of $\mathrm{CO}_{2}$ capture attracted attention of world scientists in recent years [1-3]. At present, the $\mathrm{CO}_{2}$ capture technology could be divided into three major processes: postcombustion, precombustion, and oxyfuel combustion; among them, postcombustion is the best development technology for its favorable inheritance and extensive adaptability $[4,5]$. For the $\mathrm{CO}_{2}$ separation and capture of postcombustion technology, there are four possible methods: absorption with solution [6], adsorption with solid material [7], membrane diffusion [8], and cryogenic process [9]; among them, adsorption was considered to be promising because of its low energy consumption, low equipment cost, and easiness to be applied [10]. The key to this method is to discover or design an adsorption material with high $\mathrm{CO}_{2}$ adsorption capacity and that is regenerable under mild condition.

A lot of materials have been tested in the research of $\mathrm{CO}_{2}$ adsorption. Porous material, such as zeolite and activity carbon, was investigated most extensively. However, the selectivity and adsorption capacity of $\mathrm{CO}_{2}$ on these materials are not high. At present, amino-modified porous materials gradually become the research focus since it has some advantages of liquid amine, which was used in the industrial absorption process. MCM-41 [11-13], SBA-15 [14], SBA-16 [15], activated carbon [16], and anthracites [17] all have been used as supports. The amines to modify supports contain polyethylenimine (PEI), diethylenetriamine, pentaethylenehexamine, aminpropyl triethoxysilane, and so on. The main modification methods are impregnation and grafting. Recently, some fibrous $\mathrm{CO}_{2}$ adsorbents modified with amino were reported in the literature for they have the advantage of high surface area, low price, and convenience in use. In these works, PEI was bonded to glass fiber with epoxy resin or epichlorohydrin as cross-linking agents; the highest capacity is $2.03 \mathrm{mmol} \mathrm{CO}_{2} / \mathrm{g}$ and $4.12 \mathrm{mmol}$ $\mathrm{CO}_{2} / \mathrm{g}$, respectively $[18,19]$. However, PEI could leach from adsorbents and reduce the capacity of $\mathrm{CO}_{2}$. On the other hand, too many PEI on the surface of adsorbents would lead to the formation of PEI multilayers. With the increase of thickness of PEI multilayers, the diffusion of $\mathrm{CO}_{2}$ became more difficult, which would decrease the utilization efficiency 
of PEI. Therefore, the $\mathrm{CO}_{2}$ adsorption capacity would reach maximum when PEI loading amount reached a certain value. Grafting method of amine may be a better way to introduce monolayer amino onto support compared to physical coating because the reaction is homogenous in microscale. Yang et al. prepared an adsorbent by grafting allylamine onto polyacrylonitrile (PAN) fiber with preirradiation grafting copolymerization method. Its adsorption capacity could reach $6.22 \mathrm{mmol} \mathrm{CO}_{2} / \mathrm{g}$ when the grafting degree was $60 \%$ [20].

In the present work, another amino-modified PAN (AMPAN) fiber was prepared with grafting method through the reaction of PAN fiber and triethylenetetramine (TETA) solution with the help of water. The product was characterized with FTIR, TG, BET, and EA. Its adsorption capacity of $\mathrm{CO}_{2}$ was measured by magnetic suspension balance and automatic $\mathrm{N}_{2}$ adsorption-desorption apparatus under different temperature and pressure.

\section{Experimental}

2.1. Material and Reagent. PANF was kindly provided by DongFuShengYing Company. TETA was purchased from J\&k Company. $\mathrm{CO}_{2}$ was purchased from Beijing Reagent Company. Deionized water (DI) was used in the whole study.

2.2. Preparation of AMPAN Fiber. In a typical preparation, PAN fiber was firstly extracted with methanol at boil temperature for 24 hours to remove the silicone oil at surface. Then, PAN fiber, TETA, and water (sometimes without water) were put into a glass reaction vessel with a reflux column; the mixture was stirred with a magnetic stirrer and the reaction proceeded at $110-180^{\circ} \mathrm{C}$ for $2-10$ hour. The fibers were separated from the solution after the reaction, washed with DI water till neutral, dried at $50^{\circ} \mathrm{C}$ in an oven for $10 \mathrm{~h}$, and stored in desiccators prior to use. The materials prepared at different temperatures will be designated as fiber- $T$, where $T$ is the synthesis temperature.

2.3. Characterization. Acid exchange capacities of the AMPAN fibers were determined by automatic potential titration instrument. AMPAN fiber $(0.200 \mathrm{~g})$ was immersed into $20 \mathrm{~mL}$ of $0.100 \mathrm{M} / \mathrm{L} \mathrm{HCl}$ for $0.5 \mathrm{~h}$. Then, $5 \mathrm{~mL}$ solution was fetched out and its $\mathrm{HCl}$ concentration was determined by titration with $0.100 \mathrm{M} / \mathrm{L} \mathrm{NaOH}$. The exchange capacity was calculated based on the amount of acid consumed. The $\mathrm{O}$ content of AMPAN fibers was determined by element analyzer (PerkinElmer PE 2400II). FTIR spectra were recorded on a Fourier transform infrared spectrometer (Nicolet Magna 550) in the region $4000-200 \mathrm{~cm}^{-1}$. The BET surface area of AMPAN fibers was measured at $77.3 \mathrm{~K}$ in an automatic $\mathrm{N}_{2}$ adsorption-desorption apparatus (Quantachrome, Nova 4000). Thermogravimetric analysis (TG) was carried out by a simultaneous thermal analyzer (Netzsch STA 449) at a $5 \mathrm{~K} / \mathrm{min}$ heating rate up to $473 \mathrm{~K}$ under a flow of air.

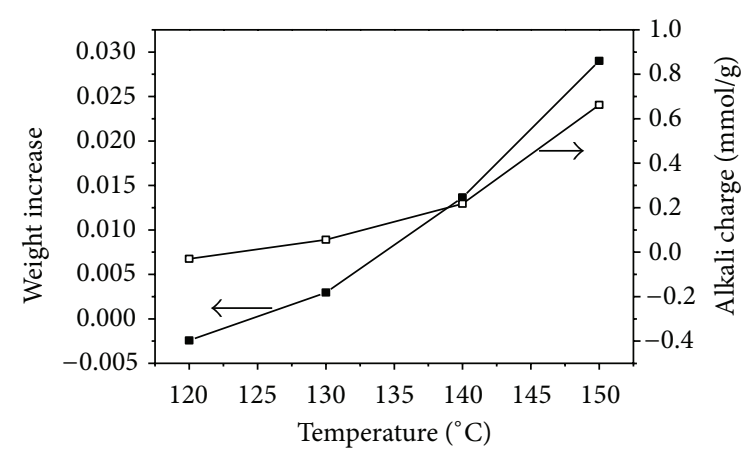

FIGURE 1: Effect of temperature on the weight-gain and alkali content of fiber without water. Reaction condition: $0.04 \mathrm{~mol}$ fiber; $0.2 \mathrm{~mol}$ TETA; $2 \mathrm{~h}$.

2.4. Adsorption Experiment. The $\mathrm{CO}_{2}$ adsorption experiments under atmospheric pressure were carried out on the automatic $\mathrm{N}_{2}$ adsorption-desorption apparatus. At first, about $0.05 \mathrm{~g}$ sample was vacuumed for $1 \mathrm{~h}$ at $180^{\circ} \mathrm{C}$, and then the sample pipe was installed on the equipment. Liquid nitrogen was used to keep the adsorption temperature at $77 \mathrm{~K}$. At last, $\mathrm{CO}_{2}$ gas was introduced into sample cell; the adsorption capacity was obtained by volumetric method. The $\mathrm{CO}_{2}$ adsorption experiments above atmospheric pressure were conducted by using magnetic suspension balance (Rubotherm). In an adsorption experiment, about 0.1 g AMPAN fiber was pretreated at $180^{\circ} \mathrm{C}$ for $0.5 \mathrm{~h}$ under the flow of $\mathrm{N}_{2}$ and degassed for $0.5 \mathrm{~h}$ in vacuum. Then, the $\mathrm{CO}_{2}$ gas was introduced into sample cell with a flow rate of $50 \mathrm{~mL} / \mathrm{min}$ for $0.5 \mathrm{~h}$. The weight variation of fiber in this process was recorded by the balance.

\section{Results and Discussion}

\subsection{Preparation of Fibers}

3.1.1. Effect of Water Amount on the Weight Increase Degree and Alkali Content of Fiber. The weight increase degree of the PAN fiber is an important index of amino grafting degree, which would increase the alkali content of the fiber. Without water, the amino grafting degree was very low. As shown in Figure 1, the weight and alkali content of fibers increased with the improvement of temperature. However, the highest weight increase degree was less than $3.0 \%$ at the highest temperature $150^{\circ} \mathrm{C}$; the corresponding alkali content was only about $0.7 \mathrm{mmol} / \mathrm{g}$.

Under the reaction condition of $40 \mathrm{mmol}$ PAN fiber and $200 \mathrm{mmol}$ TETA at $150^{\circ} \mathrm{C}$ for $2 \mathrm{~h}$, with the increase of water amount from 0 to $14.4 \mathrm{~g}$, the weight of fiber increased from $2.9 \%$ to $48.8 \%$ firstly and then reduced to $19.3 \%$ and at last to $3.8 \%$ (see Figure 2). The alkali content variation characterization of the prepared AMPAN fiber was consistent with the weight variation characterization. It increased from 0.7 to $3.1 \mathrm{mmol} / \mathrm{g}$ and then reduced to 2.2 and at last to $0.2 \mathrm{mmol} / \mathrm{g}$. The reason for the decrease of weight and alkali content was that the excess water would decrease the reaction temperature of solution despite the fact that the temperature 


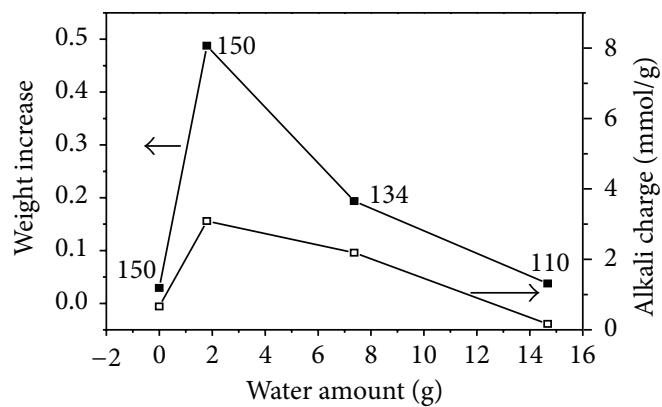

FIGURE 2: Effect of water amount on the weight increase degree and alkali content of fiber. Reaction condition: $0.04 \mathrm{~mol}$ fiber; $0.2 \mathrm{~mol}$ TETA; $150^{\circ} \mathrm{C} ; 2 \mathrm{~h}$.

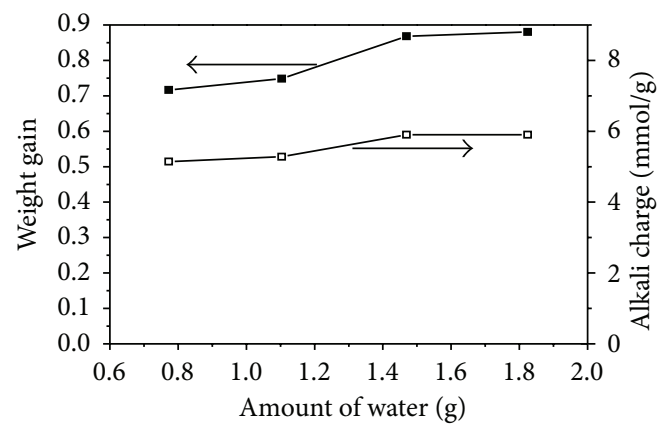

FIGURE 3: Effect of water amount on the weight increase degree and alkali content of fiber. Reaction condition: $0.04 \mathrm{~mol}$ fiber; $0.2 \mathrm{~mol}$ TETA; $160^{\circ} \mathrm{C} ; 2 \mathrm{~h}$.

of oil bath was the same. It was observed that the temperature of reaction solution was $150^{\circ} \mathrm{C}$ when the water amount was $1.8 \mathrm{~g}$ or without water, while the reaction temperature was only 134 and $110^{\circ} \mathrm{C}$ when the water amount was $7.2 \mathrm{~g}$ and $14.4 \mathrm{~g}$, respectively, although the oil bath temperature was still $150^{\circ} \mathrm{C}$.

Under the same reaction temperature, the effect of water amount on the weight increase degree was further investigated. As shown in Figure 3, with the amount of water increased from 0.72 to $1.80 \mathrm{~g}$, the weight of fiber increased from $72 \%$ to $88 \%$. The alkali content of the fiber also increased from 5.1 to $5.9 \mathrm{mmol} / \mathrm{g}$. This phenomenon could be explained by Le Chatelier's principle: the yield of product would increase along with the increase of reactant concentration.

3.1.2. Effect of Reaction Temperature. The effect of reaction temperature on the weight increase degree and alkali content was investigated under the following conditions: $0.04 \mathrm{~mol}$ fiber; $0.2 \mathrm{~mol}$ TETA; $0.1 \mathrm{~mol}$ water; $2 \mathrm{~h}$. The results indicated that the weight of fiber increased monotonously from $49 \%$ to $150 \%$ with the improvement of temperature from 150 to $180^{\circ} \mathrm{C}$ (see Figure 4 ). At the same time, the alkali content of fiber increased from 3.1 to $6.6 \mathrm{mmol} / \mathrm{g}$. However, once the temperature was over $220^{\circ} \mathrm{C}$, the fiber would dissolve into the TETA solution. There are two possible reasons for the phenomenon: (1) TETA was grafted on the surface of PAN fiber by the reaction, which enhances the mutual effect

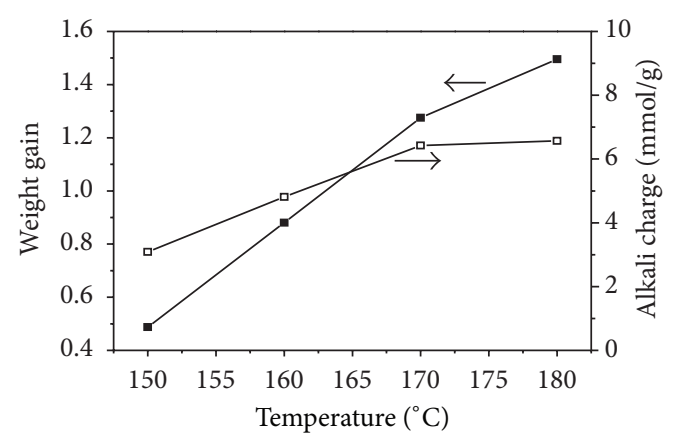

FIGURE 4: Effect of temperature on the weight increase degree and alkali content of fiber. Reaction condition: $0.04 \mathrm{~mol}$ fiber; $0.2 \mathrm{~mol}$ TETA; $0.1 \mathrm{~mol}$ water; $2 \mathrm{~h}$.

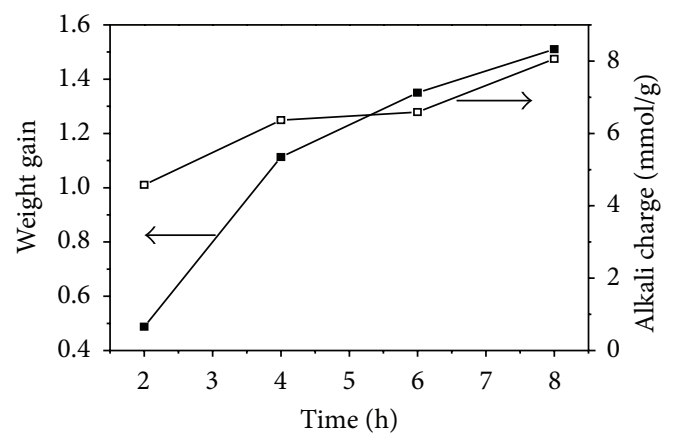

FIGURE 5: Effect of time on the weight increase degree and alkali content of fiber. Reaction condition: $0.04 \mathrm{~mol}$ fiber; $0.2 \mathrm{~mol}$ TETA; $0.1 \mathrm{~mol}$ water; $150^{\circ} \mathrm{C}$.

between AMPAN fiber and solvent TETA through hydrogenbond interaction; (2) the carbon-carbon bond of PAN fiber would be broken at high temperature.

3.1.3. Effect of Reaction Time. The effect of reaction time on the weight increase degree and alkali content was investigated under the following conditions: 0.04 mol fiber; 0.2 mol TETA; $0.1 \mathrm{~mol}$ water; $150^{\circ} \mathrm{C}$. As shown in Figure 5, with the increase of reaction time from 2 to $8 \mathrm{~h}$, the weight and alkali content of fiber would increase from $49 \%$ to $151 \%$ and from 4.6 to $8.1 \mathrm{mmol} / \mathrm{g}$, respectively.

\subsection{Characterization of Fibers}

3.2.1. The Effect of Reaction Condition on the Oxygen Content of AMPAN Fibers. Figure 6 shows the effect of reaction condition on the oxygen content of AMPAN fibers. With the increase of reaction temperature, time, and water amount, the oxygen content of fiber also increased. These results are consistent with the conclusions of previous discussion. The highest oxygen content was $19.8 \%$ at $180^{\circ} \mathrm{C}$, which indicated that the hydrolysis degree of cyano group was the deepest under this condition. 

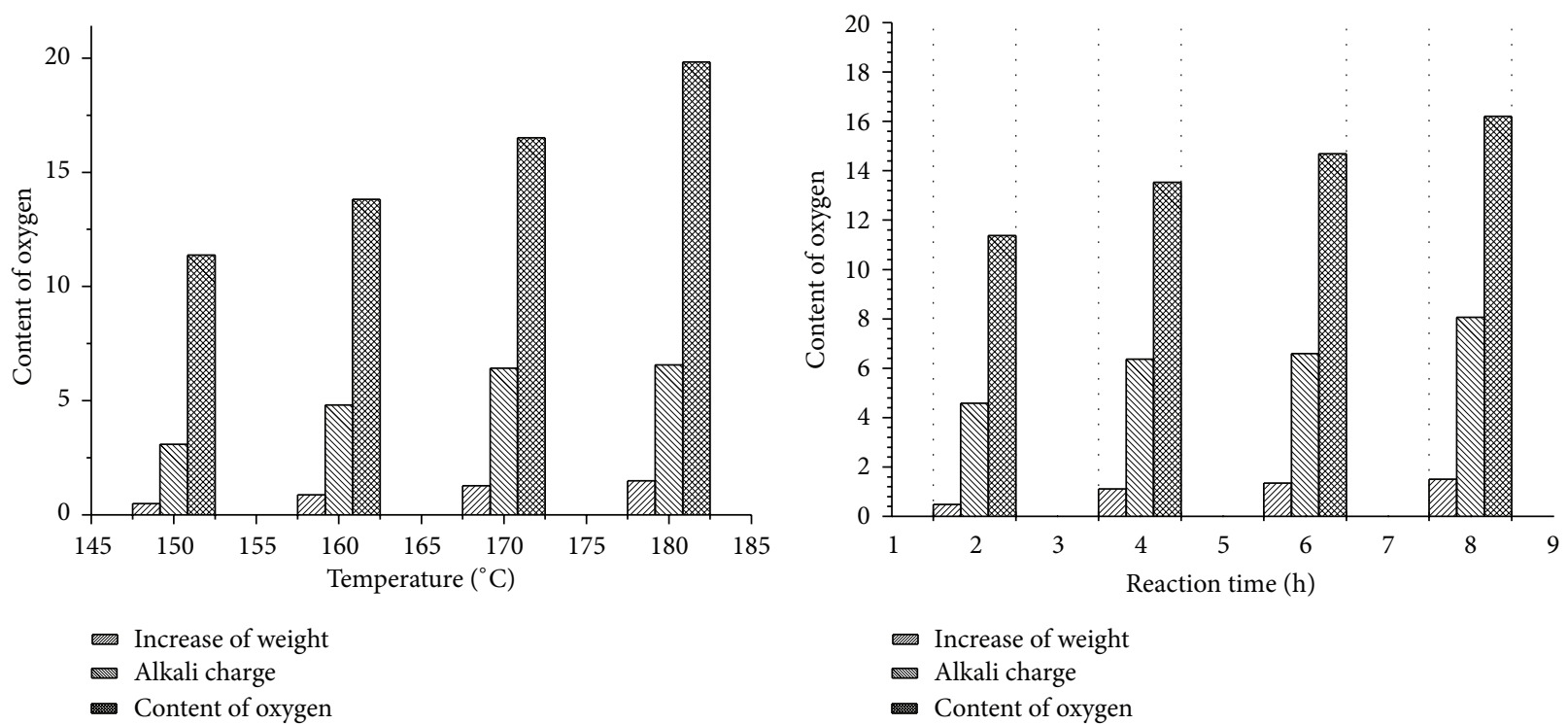

(a)

(b)

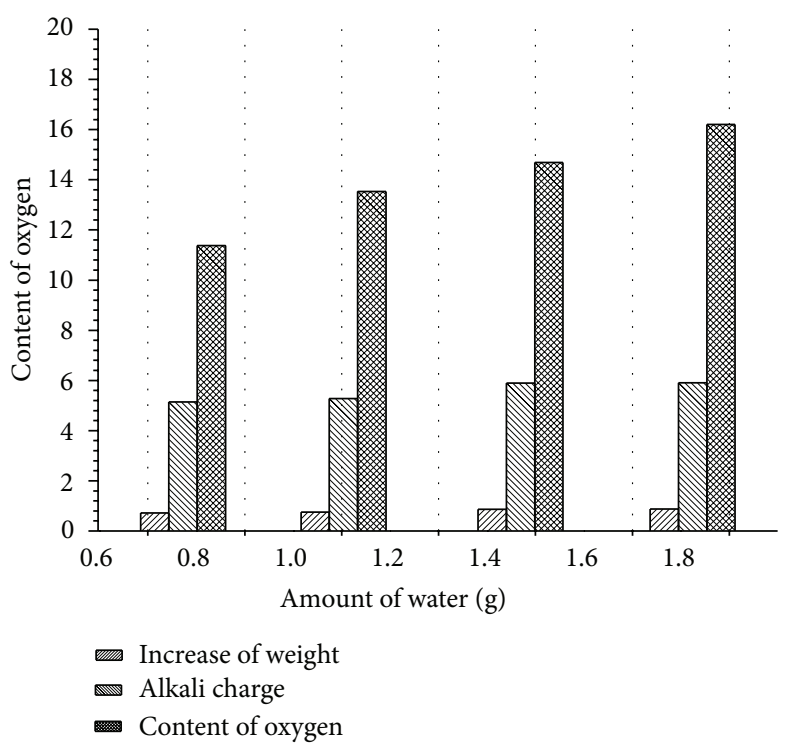

(c)

FIGURE 6: Effect of reaction condition on the oxygen content of AMPAN fiber: (a) temperature; (b) time; (c) amount of water.

3.2.2. FTIR Spectrum of Fibers. Figure 7 shows the FTIR spectra of PAN fiber and AMPAN fiber. The band in the spectrum of PAN fiber could be assigned as follows: $2945 \mathrm{~cm}^{-1}$ was the stretching vibration of $\mathrm{CH}, \mathrm{CH}_{2}$, and $\mathrm{CH}_{3}$; $2244 \mathrm{~cm}^{-1}$ was the stretching vibration of $\mathrm{CN} ; 1455 \mathrm{~cm}^{-1}$ was the bending stretching vibration of $\mathrm{CH}_{2}$ and $\mathrm{CH}_{3}$. After reaction with TETA at different temperatures, some new peaks appeared in the spectrum of prepared AMPAN fiber: the band at $2840 \mathrm{~cm}^{-1}$ was the symmetry stretching vibration of $\mathrm{CH}_{2}$ and the band at 1668,1558 , and $1120 \mathrm{~cm}^{-1}$ was the $\mathrm{C}=\mathrm{O}$ stretching vibration, $\mathrm{N}-\mathrm{H}$ bending vibration, and $\mathrm{C}-\mathrm{N}$ bending vibration in imide, respectively. At the same time, the band at $2244 \mathrm{~cm}^{-1}$ reduced more and more significantly with the increase of temperature from 150 to $180^{\circ} \mathrm{C}$. These results indicated that imide group was introduced to the surface of PAN fiber. The reaction mechanism in the preparation of AMPAN fiber from PAN fiber and TETA could be expressed by Scheme 1.

3.2.3. TG Analysis of Fibers. The TGA spectra of AMPAN fibers prepared under different temperature was presented in Figure 8. The mass loss profiles are similar for all the AMPAN fibers. In the TG curves, two weight loss steps were observed at 85 and $160^{\circ} \mathrm{C}$. The first weight loss could be attributed to desorption of the moisture. The second one may be assigned to desorption of $\mathrm{CO}_{2}$, which were adsorbed in the previous 


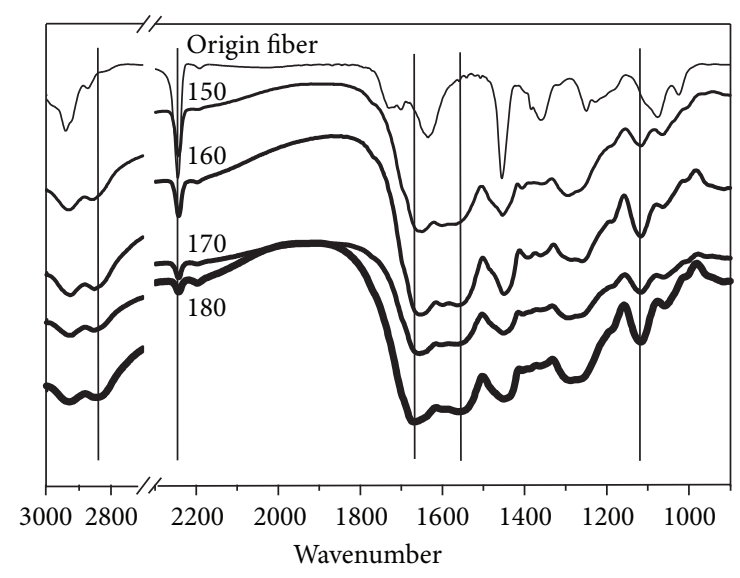

FIGURE 7: FTIR spectrum of fiber prepared at different temperatures.

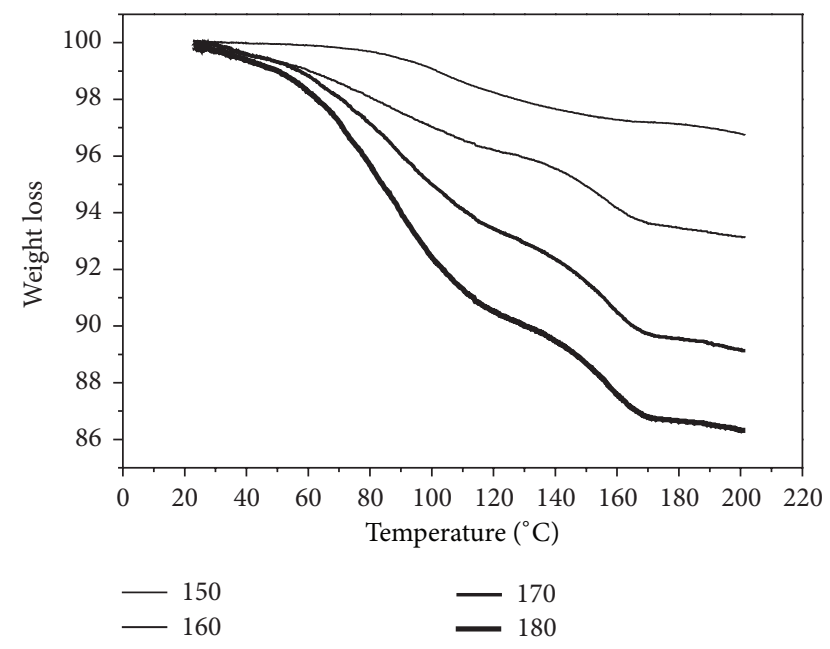

FIgURE 8: TG analysis of fiber prepared at different temperatures.

preparation process of AMPAN fiber. The highest weight loss was observed to be $14 \%$ for the fiber prepared at $180^{\circ} \mathrm{C}$.

3.2.4. Surface Area of Fiber. The specific surface area of AMPAN fibers was determined by Brunauea-Emmet-Teller (BET) method based on $\mathrm{N}_{2}$ adsorption isotherm at $77 \mathrm{~K}$. The results were presented in Table 1 . It was found that the surface area of fibers increased monotonously from 0.878 to $1.238 \mathrm{~m}^{2} / \mathrm{g}$, with the increase of preparing temperature from 150 to $180^{\circ} \mathrm{C}$. These results indicate that reaction temperature did not affect the surface area of fiber significantly; they are all small.

3.3. Adsorption Property of AMPAN Fiber. The adsorption isotherms of $\mathrm{CO}_{2}$ onto AMPAN fiber prepared at different temperatures were obtained at pressure from 0 to 15 bar. Figure 9(a) shows the $\mathrm{CO}_{2}$ adsorption data of fiber at $77 \mathrm{~K}$ when the pressure is lower than atmospheric pressure. The adsorption capacities of fibers varied according to the following order: fiber-180 > fiber-170 > fiber-160 > fiber-150. The highest capacity was only $0.27 \mathrm{~mL} / \mathrm{g}$ at atmospheric pressure.

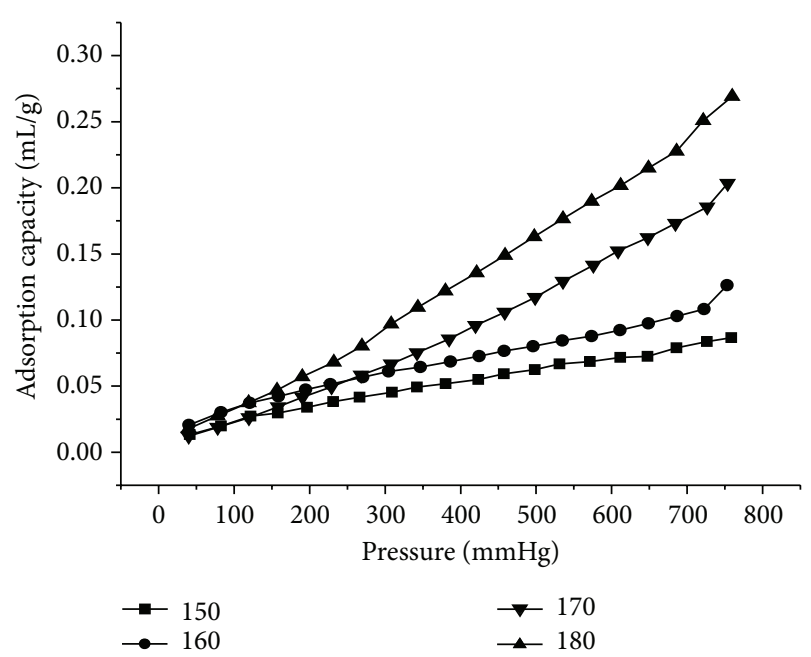

(a)

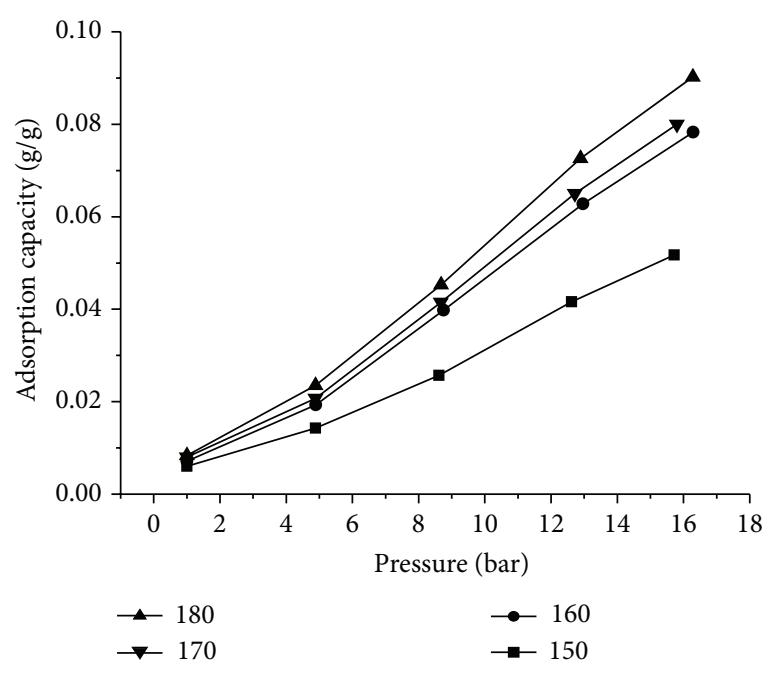

(b)

FIGURE 9: $\mathrm{CO}_{2}$ adsorption capacity of fiber at different pressure: (a) pressure lower than atmospheric pressure; (b) pressure higher than 1 bar.

Figure 9 (b) shows the $\mathrm{CO}_{2}$ adsorption data of fiber at $50^{\circ} \mathrm{C}$ above the atmospheric pressure. The capacities of fibers variation characterization are consistent with that obtained under the atmospheric pressure. The highest capacity was $0.09 \mathrm{~g} / \mathrm{g}$ for fiber 180. These results indicated that the adsorption capacity of AMPAN fiber was much lower than that of PEI and allylamine modified PAN fiber reported previously. The reason may be due to the small surface area of AMPAN fiber. Further research was not conducted for its adsorption capacity which was far from satisfactory.

\section{Conclusions}

A serial of amino-modified PAN fibers were synthesized by the reaction of PAN fiber with TETA in the presence of water. The weight and alkali content, namely, amino grafting degree, would be improved by prolonging reaction time 
<smiles>NCCNCCNCCNCCNCC[NH3+]</smiles>

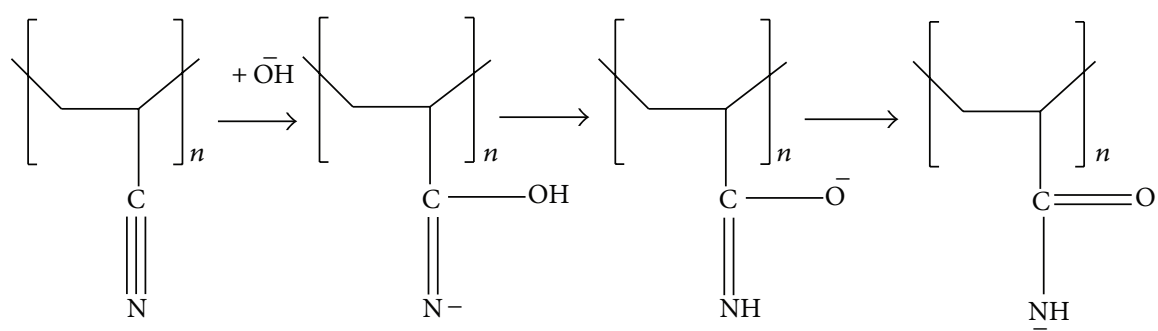<smiles></smiles><smiles>CCC(C)C(C)C(=O)NCCNCCNCC[NH3+]</smiles>

SCHEME 1: Reaction mechanism of conversion from PAN to AMPAN fiber.

TABLE 1: Surface of AMPAN fiber prepared at different temperatures.

\begin{tabular}{lcccc}
\hline Fiber & Fiber $150^{\circ} \mathrm{C}$ & Fiber $160^{\circ} \mathrm{C}$ & Fiber $170^{\circ} \mathrm{C}$ & Fiber $180^{\circ} \mathrm{C}$ \\
\hline $\begin{array}{l}\text { Surface area } \\
\left(\mathrm{m}^{2} / \mathrm{g}\right)\end{array}$ & 0.878 & 0.976 & 1.048 & 1.238 \\
\hline
\end{tabular}

and increasing reaction temperature. However, proper water amount was needed to improve the amino grafting degree, because excess water would reduce the temperature of the reaction solution. The oxygen content analysis and FTIR characterization results indicated that TETA was grafted onto the surface of PAN fiber. TG analysis demonstrated that the fibers would desorb water and $\mathrm{CO}_{2}$ at about 85 and $160^{\circ} \mathrm{C}$, respectively, which were adsorbed in the preparation process. The adsorption capacities of AMPAN fibers were very low, which may be attributed to its low surface area.

\section{Conflict of Interests}

The authors declared that they have no conflict of interests to this work.

\section{Acknowledgments}

The authors acknowledge the financial support from State Key Laboratory of Chemical Engineering (No. SKL-ChE12A03) and National Natural Science Foundation of China (Grant No. 21306071).

\section{References}

[1] E. S. Rubin, C. Chen, and A. B. Rao, "Cost and performance of fossil fuel power plants with $\mathrm{CO}_{2}$ capture and storage," Energy Policy, vol. 35, no. 9, pp. 4444-4454, 2007.

[2] J. C. Abanades, E. S. Rubin, and E. J. Anthony, "Sorbent cost and performance in $\mathrm{CO}_{2}$ capture systems," Industrial and Engineering Chemistry Research, vol. 43, no. 13, pp. 3462-3466, 2004.

[3] R. Steeneveldt, B. Berger, and T. A. Torp, " $\mathrm{CO}_{2}$ capture and storage: closing the knowing-doing gap," Chemical Engineering Research and Design, vol. 84, no. 9, pp. 739-763, 2006.

[4] J. Davison, "Performance and costs of power plants with capture and storage of $\mathrm{CO}_{2}$," Energy, vol. 32, no. 7, pp. 1163-1176, 2007.

[5] C. Kunze and H. Spliethoff, "Assessment of oxy-fuel, pre- and post-combustion-based carbon capture for future IGCC plants," Applied Energy, vol. 94, pp. 109-116, 2012. 
[6] M. Hasib-ur-Rahman, M. Siaj, and F. Larachi, "Ionic liquids for $\mathrm{CO}_{2}$ capture-development and progress," Chemical Engineering and Processing: Process Intensification, vol. 49, no. 4, pp. 313322, 2010.

[7] S. Araki, H. Doi, Y. Sano, S. Tanaka, and Y. Miyake, "Preparation and $\mathrm{CO}_{2}$ adsorption properties of aminopropyl-functionalized mesoporous silica microspheres," Journal of Colloid and Interface Science, vol. 339, no. 2, pp. 382-389, 2009.

[8] A. Brunetti, F. Scura, G. Barbieri, and E. Drioli, "Membrane technologies for $\mathrm{CO}_{2}$ separation," Journal of Membrane Science, vol. 359, no. 1-2, pp. 115-125, 2010.

[9] K. E. Zanganeh, A. Shafeen, and C. Salvador, " $\mathrm{CO}_{2}$ capture and development of an advanced pilot-scale cryogenic separation and compression unit," Energy Procedia, vol. 1, pp. 247-252, 2009.

[10] S. Choi, J. H. Drese, and C. W. Jones, "Adsorbent materials for carbon dioxide capture from large anthropogenic point sources," ChemSusChem, vol. 2, no. 9, pp. 796-854, 2009.

[11] X. Xu, C. Song, B. G. Miller, and A. W. Scaroni, "Adsorption separation of carbon dioxide from flue gas of natural gas-fired boiler by a novel nanoporous "molecular basket" adsorbent," Fuel Processing Technology, vol. 86, no. 14-15, pp. 1457-1472, 2005.

[12] X. Xu, C. Song, J. M. Andresen, B. G. Miller, and A. W. Scaroni, "Novel polyethylenimine-modified mesoporous molecular sieve of MCM-41 type as high-capacity adsorbent for $\mathrm{CO}_{2}$ capture," Energy and Fuels, vol. 16, no. 6, pp. 1463-1469, 2002.

[13] X. Xu, C. Song, J. M. Andrésen, B. G. Miller, and A. W. Scaroni, "Preparation and characterization of novel $\mathrm{CO}_{2}$ "molecular basket" adsorbents based on polymer-modified mesoporous molecular sieve MCM-41," Microporous and Mesoporous Materials, vol. 62, no. 1-2, pp. 29-45, 2003.

[14] H. Zhao, J. Hu, J. Wang, L. Zhou, and H. Liu, "CO${ }_{2}$ capture by the amine-modified mesoporous materials," Acta PhysicoChimica Sinica, vol. 23, no. 6, pp. 801-806, 2007.

[15] C. Knöfel, J. Descarpentries, A. Benzaouia et al., "Functionalised micro-/mesoporous silica for the adsorption of carbon dioxide," Microporous and Mesoporous Materials, vol. 99, no. 12, pp. 79-85, 2007.

[16] M. G. Plaza, C. Pevida, A. Arenillas, F. Rubiera, and J. J. Pis, " $\mathrm{CO}_{2}$ capture by adsorption with nitrogen enriched carbons," Fuel, vol. 86, no. 14, pp. 2204-2212, 2007.

[17] M. M. Maroto-Valer, Z. Tang, and Y. Zhang, " $\mathrm{CO}_{2}$ capture by activated and impregnated anthracites," Fuel Processing Technology, vol. 86, no. 14-15, pp. 1487-1502, 2005.

[18] P. Li, B. Ge, S. Zhang, S. Chen, Q. Zhang, and Y. Zhao, " $\mathrm{CO}_{2}$ capture by polyethylenimine-modified fibrous adsorbent," Langmuir, vol. 24, no. 13, pp. 6567-6574, 2008.

[19] P. Li, S. Zhang, S. Chen, Q. Zhang, J. Pan, and B. Ge, "Preparation and adsorption properties of polyethylenimine containing fibrous adsorbent for carbon dioxide capture," Journal of Applied Polymer Science, vol. 108, no. 6, pp. 3851-3858, 2008.

[20] Y. Yang, H. Li, S. Chen, Y. Zhao, and Q. Li, "Preparation and characterization of a solid amine adsorbent for capturing $\mathrm{CO}_{2}$ by grafting allylamine onto PAN fiber," Langmuir, vol. 26, no. 17, pp. 13897-13902, 2010. 

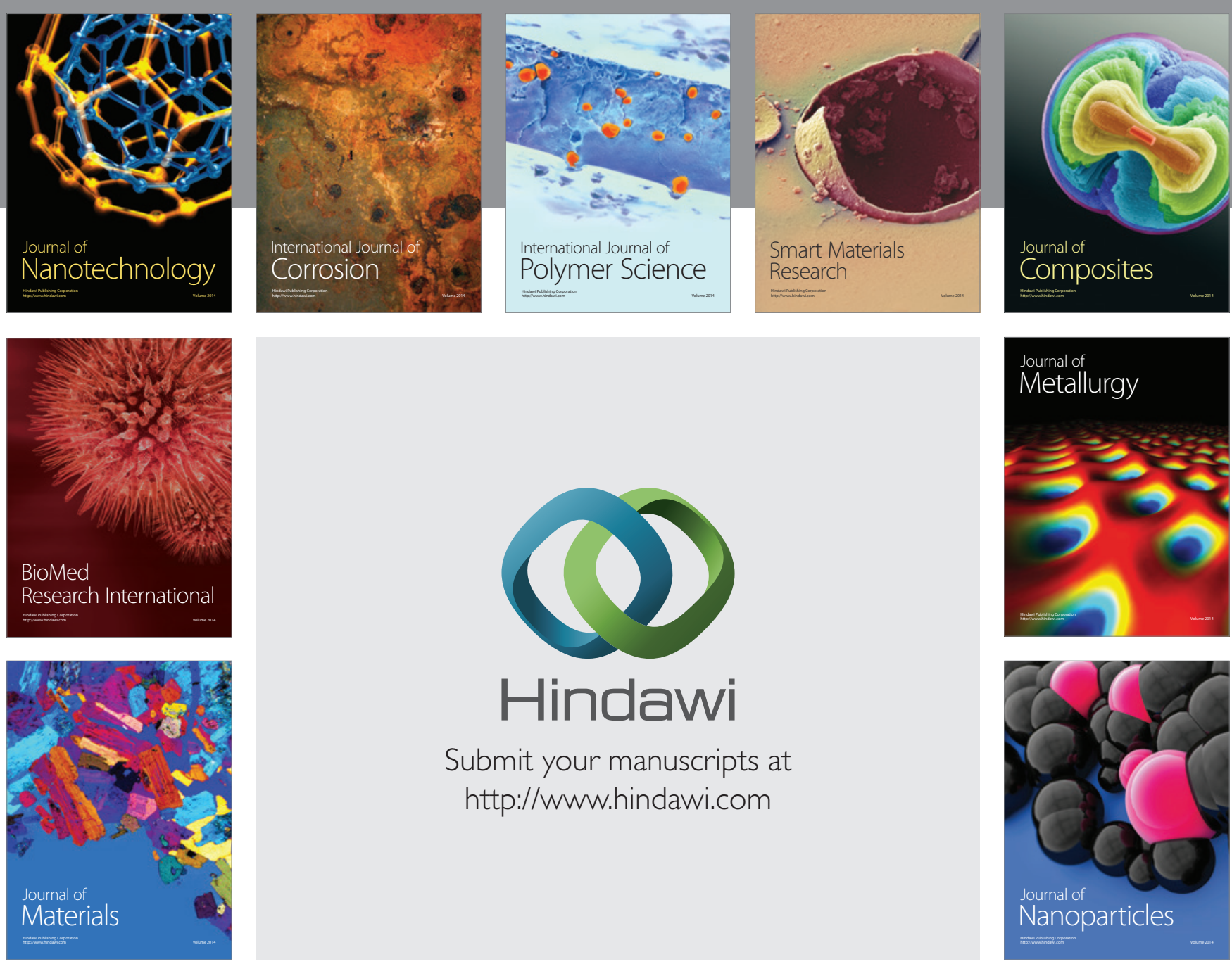

Submit your manuscripts at http://www.hindawi.com
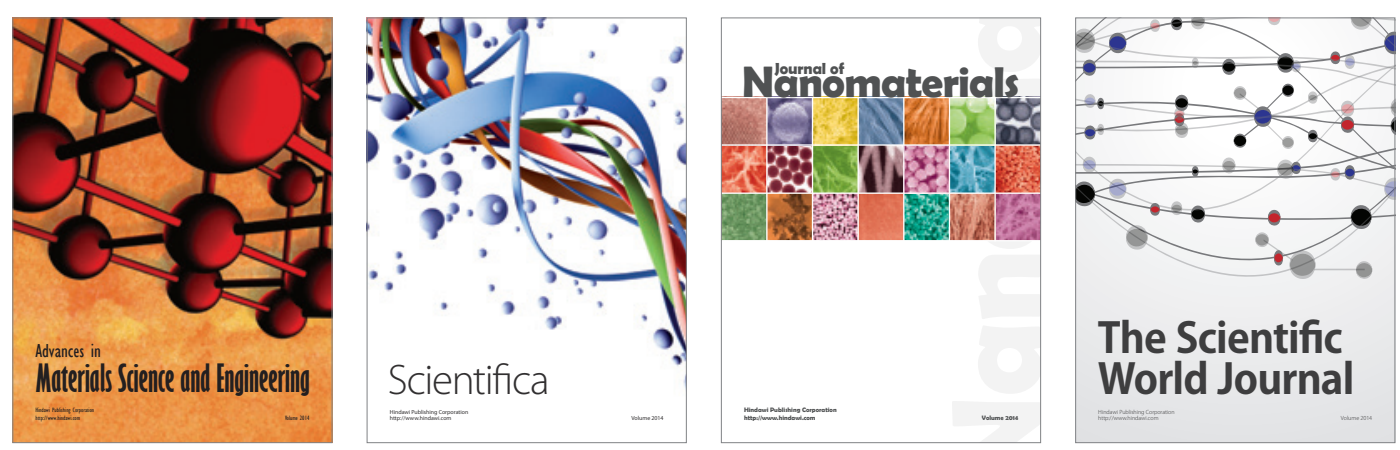

\section{The Scientific World Journal}
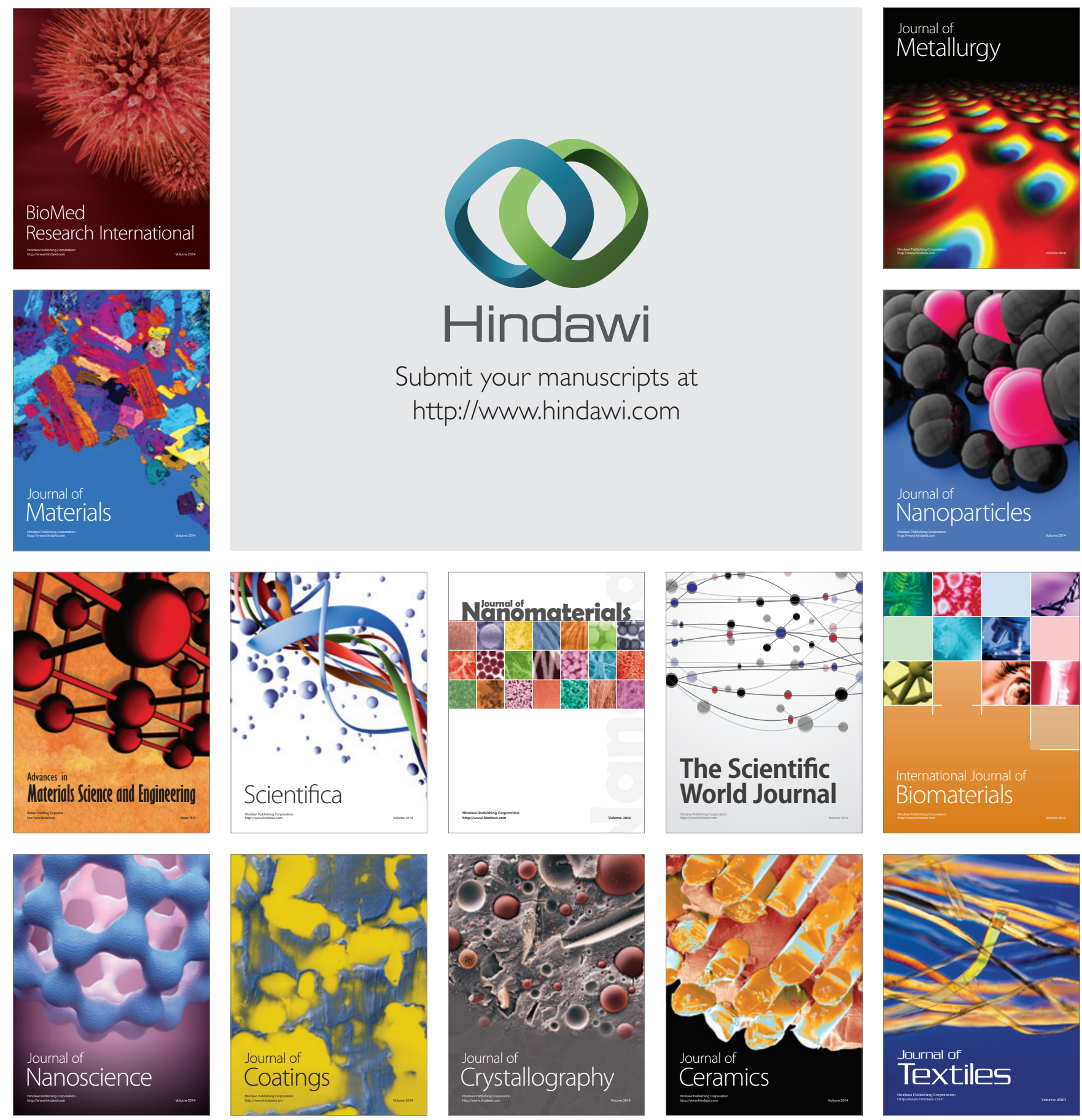